\title{
Brain Development of the Preterm Neonate After Neonatal Hydrocortisone Treatment for Chronic Lung Disease
}

\author{
MANON J.N.L. BENDERS, FLORIS GROENENDAAL, FRANK VAN BEL, RUSSIA HA VINH, JESSICA DUBOIS, \\ FRANÇOIS LAZEYRAS, SIMON K. WARFIELD, PETRA S. HÜPPI, AND LINDA S. DE VRIES
}

\author{
Department of Neonatology [M.J.N.L.B., F.G., F.B., L.S.V.], Wilhelmina Children's Hospital, Utrecht 3508 AB, The Netherlands; \\ Department of Pediatrics [M.J.N.L.B., R.H.V., J.D., F.L., P.S.H.], University Children's Hospital, Geneva 1211, Switzerland; \\ Computational Radiology Laboratory Radiology Department [S.K.W.], Children's Hospital Boston and Harvard Medical School Boston, \\ Boston, Massachusetts 02115
}

\begin{abstract}
Previous studies reported impaired cerebral cortical gray matter (CGM) development and neurodevelopmental impairment after neonatal dexamethasone treatment for chronic lung disease (CLD) in preterm newborns. No long-term effects on neurocognitive outcome have yet been shown for hydrocortisone treatment. A prospective study was performed to evaluate the brain growth at term in preterm infants who did receive neonatal hydrocortisone for CLD. Thirty-eight preterm infants ( $n=19$ hydrocortisone, $n=19$ controls) were matched for gestational age at birth. Gestational age and birth weight were $27.0 \pm 1.4$ versus $27.6 \pm 1.1 \mathrm{wk}(p=\mathrm{ns})$ and $826 \pm 173$ versus $1017 \pm 202 \mathrm{~g}$, respectively $(p<0.05)$. Infants were studied at term equivalent age. Hydrocortisone was started with a dose of 5 $\mathrm{mg} / \mathrm{kg} / \mathrm{d}$ for $1 \mathrm{wk}$, followed by a tapering course over $3 \mathrm{wk}$. A 3D-MRI technique was used to quantify cerebral tissue volumes: CGM, basal ganglia/thalami, unmyelinated white matter, myelinated white matter, cerebellum, and cerebrospinal fluid. Infants who were treated with hydrocortisone had more severe respiratory distress. There were no differences in cerebral tissue volumes between the two groups at term equivalent age. In conclusion, no effect on brain growth, measured at term equivalent age, was shown after treatment with hydrocortisone for CLD. (Pediatr Res 66: 555-559, 2009)
\end{abstract}

$\mathrm{N}^{\mathrm{e}}$ eonatal corticosteroid exposure for treatment of chronic lung disease (CLD) in preterm newborns, in particular dexamethasone, is known to have an adverse effect on the cerebral development during fetal and early postnatal life. Uno et al. (1) reported dexamethasone-induced degeneration and depletion of hippocampal pyramidal and dentate granular neurons in Rhesus monkeys. Subsequently, MRI of the brain at 20 mo of age showed a $30 \%$ reduction in size and segmental volumes of the hippocampus in dexamethasone-treated animals compared with vehicle-treated animals.

The adverse long-term effect of neonatal dexamethasone therapy on neurodevelopmental outcome has also been extensively reported in preterm infants treated for CLD (2-4). Dexamethasone treatment was associated with an increased risk of cerebral palsy (2-4) and an adverse effect on cognitive function (2-4). Furthermore, it has been shown that neonatal

Received February 9, 2009; accepted June 17, 2009.

Correspondence: Manon Benders, M.D., Ph.D., Department of Neonatology, Wilhelmina Children's Hospital, KE 04.123.1, Post Box 85090, 3508 AB Utrecht, The Netherlands; e-mail: m.benders@umcutrecht.nl

Supported by Royal Netherlands Academy of Arts and Sciences, the Termeulen fund and IPRF young investigator Fellowship, and SNF No 32-102127 and No 3200B0113632 to PSH, and, in part, by NIH grants R01 RR021885 and R01 GM074068. dexamethasone therapy affected the regional brain development (1). Advanced quantitative MRI technologies have shown a reduction in total cerebral tissue volume, in particular the cerebral cortical gray matter (CGM) volume (5) and the cerebellar volume in newborn infants treated with dexamethasone (6).

These findings suggest that there is a need for a safer alternative for the treatment of CLD. Data published so far, using other corticosteroids, such as hydrocortisone for treatment of CLD are still scarce. In the Wilhelmina Children's Hospital, hydrocortisone has been used to treat CLD since the late 70s. Hydrocortisone was shown to be equally effective in treatment of CLD in a retrospective observational study (7). This retrospective study also showed that children treated with dexamethasone more often needed special education than matched controls who were not treated with dexamethasone. Moreover, in contrast to dexamethasone, recent studies found no differences between children who were treated with hydrocortisone in the neonatal period compared with children who did not need hydrocortisone treatment with respect to longterm cognitive and neuromotor outcome (8-10). Furthermore, Lodygensky et al. (8) showed no differences in the brain tissue volumes and neurodevelopmental outcome in children assessed at the age of $8 \mathrm{y}$ treated with neonatal hydrocortisone compared with children who did not receive any hydrocortisone during their neonatal course. CGM and hippocampal volumes were comparable for both groups.

All hydrocortisone studies mentioned earlier were observational and retrospective. Therefore, we decided to perform a prospective study to evaluate the brain development at term equivalent age in preterm infants who were treated with hydrocortisone for CLD and compared the results to a group of preterm infants who did not receive hydrocortisone.

\section{PATIENTS AND METHODS}

Patients. Twenty-seven preterm infants, born in the Wilhelmina Children's Hospital, were enrolled into the study at the time they were treated with hydrocortisone for severe respiratory problems. Hydrocortisone was started at a postnatal age of at least $1 \mathrm{wk}$ in an infant who was ventilator dependent with increasing oxygen requirements, which could not be explained by infection or

Abbreviations: CGM, cortical gray matter; CLD, chronic lung disease; CSF, cerebrospinal fluid; SGM, subcortical gray matter 
a hemodynamically significant patent ductus arteriosus (PDA), but was considered due to severe infant respiratory distress syndrome (IRDS) and/or development of CLD, despite optimal supportive therapy (diuretics, fluid restriction, and pulmonary aerosols). Neonatal hydrocortisone treatment started with a dose of $5 \mathrm{mg} / \mathrm{kg} / \mathrm{d}$, divided into four doses for 1 week, followed by a tapering course of 3,2 , and 1 dose(s) every $5 \mathrm{~d}$ (a total dose hydrocortisone of $3.75,2.5$, and $1.25 \mathrm{mg} / \mathrm{kg} / \mathrm{d}$, respectively).

Children with cerebral lesions, more severe than grade 1 germinal matrix hemorrhage-intraventricular hemorrhage (GMH-IVH) or PVL grade I (periventricular echogenicity, being present for more than 7 days) on cranial ultrasound were not included in the study. Infants with intrauterine growth retardation were not eligible for the study. Eight of the 27 infants were excluded because of lack of parental consent $(n=5)$, cerebral pathology visible on cranial ultrasound $(n=2$; one was suspected to have precystic PVL on cerebral ultrasound, and the other infant had severe unilateral dilatation of the occipital horn of the lateral ventricle at the moment of inclusion). Furthermore, one patient was excluded because of movement artifacts on MR images. Eventually, 19 hydrocortisone-treated infants were included in the study.

These infants were matched for gestational age and whenever possible also for gender and respiratory status. Three-matched controls were born in Utrecht and 16 in Geneva. These children did not receive postnatal corticosteroids and had no intracranial lesions on their cranial ultrasounds (worse than grade I GMH-IVH, PVL grade II-III) or MRI at term equivalent age. All these children had sequential cerebral ultrasound examinations after birth according to similar ultrasound protocols in Utrecht and Geneva.

The study was approved by the local ethics committees. Written informed parental consent was always obtained for the children included in the study.

Data acquisition. Most infants were imaged with sedation to prevent image degradation from motion artifacts. A neonatologist was always present during the examination. During MR examination, the neonates were placed in a vacuum fixation pillow (Med Vac Infant Immobilizer Bag, CFI Medical Solutions, Fenton, MI). Monitoring was performed using pulse oximetry (Nonin, Minneapolis, MN) and respiration rate was observed using the standard Philips equipment (Philips Medical Systems, Best, The Netherlands). For hearing protection Minimuffs (Natus Medical Incorporated, San Carlos, CA) were used.

Both in Utrecht and Geneva, we used a 1.5T Philips MR scanner (Philips Medical Systems). The protocol consisted of a 3D T1 fast-gradient echo sequence [repetition time $(\mathrm{TR})=15 \mathrm{~ms}$, echo time $(\mathrm{TE})=4.4 \mathrm{~ms}$, flip angle $25^{\circ}$ ], field of view (FOV) $18 \mathrm{~cm}$ and a double echo (T2-and proton-density) fast-spin echo sequence $(\mathrm{TR}=3500 \mathrm{~ms}, \mathrm{TE}=30 / 150 \mathrm{~ms}$, interleaved, no gap acquisition). Both sequences were acquired with coronal slices of $1.5 \mathrm{~mm}$ and in plane resolution of $0.7 \times 0.7 \mathrm{~mm}^{2}$, (FOV $18 \times 18 \mathrm{~cm}^{2}$, matrix $256 \times 256$ ).

Data postprocessing. 3D Volumetric MRI: Post acquisition processing was carried out on a workstation (Sun Microsystems, Mountain View, CA) with specially developed software $(11,12)$. The T2-weighted and proton density-weighted images were registered to the T1 weighted images. Segmentations of the intracranial cavity, cerebrospinal fluid (CSF), and four tissue classes (CGM, subcortical gray matter (SGM), unmyelinated white matter (UMWM) and myelinated white matter (MWM)) were obtained using a semi-automatic segmentation method $(13,14)$. Sample voxels were selected interactively and optimal estimation of the distribution of MRI signal intensities associated with each type of tissue was estimated. Initial estimates for the tissue classifiers were manually defined by a single investigator (M.B.). An anatomical template was aligned with the intracranial cavity of the subject and used to disambiguate the segmentation of tissues that have overlapping signal intensity characteristics but nonoverlapping spatial distribution. The volume of each tissue class was quantified (Fig. 1). The sum of CGM, SGM, UMWM, and MWM defined the total brain cerebral tissue volume. Total cerebral tissue volume and CSF represented the intracranial volume.

Cerebellar volumes were measured by manual outlining on the T2weighted images of the registered 3D MRI data using Slicer (www.slicer.org) (15). The segmentation was started on coronal slices and then corrected on sagittal slices. Three-dimensional reconstruction of the cerebellum was performed to check the quality of the segmentation (Fig. 2). A single investigator (R.H.V.) performed all manual outlining of the cerebellum, with an intra-rater reliability coefficient (five MRI scans) of $\alpha=0.96$.

Statistical analysis. Data are summarized as mean \pm SD or as median and ranges where appropriate. Differences between groups in volume of cerebral tissues and in clinical data were evaluated with one factorial ANOVA, with pair wise multiple comparison procedures, followed by a posthoc Bonferroni test if a significant difference was detected, or $\chi^{2}$ test when categorical variables were compared. We anticipated that we needed 12 infants in each group to detect the $35 \%$ difference in CGM observed following dexamethasone treatment. Furthermore, we did a bio-equivalence means power analysis with a sample size of 20 , which concluded equivalence between groups. This means that it will be allowed to conclude equivalence between the groups

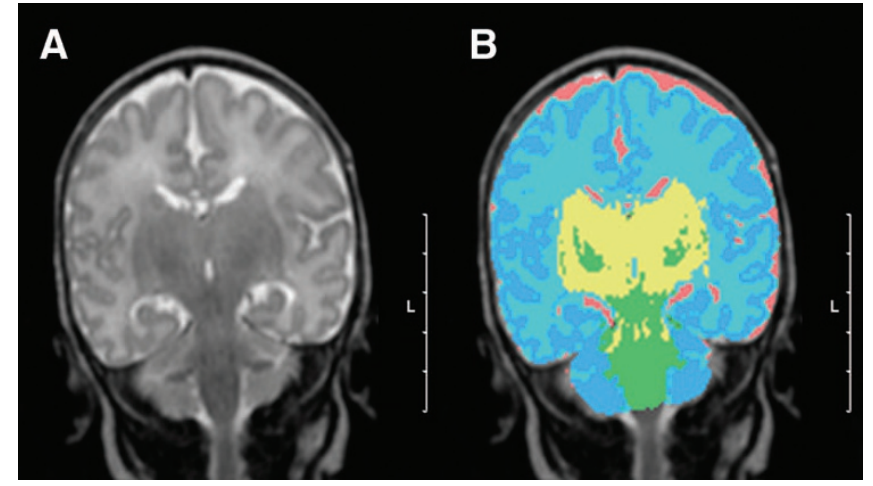

Figure 1. $A, \mathrm{~T} 2$-weighted $\mathrm{MR}$ image in coronal plane. $B$, Final segmented image depicting CGM in dark blue, UNMW in light blue, CSF in pink, MWM in green, and SGM (basal ganglia) in yellow. (Scale bar $=5 \mathrm{~cm}, \mathrm{~L}=$ left).

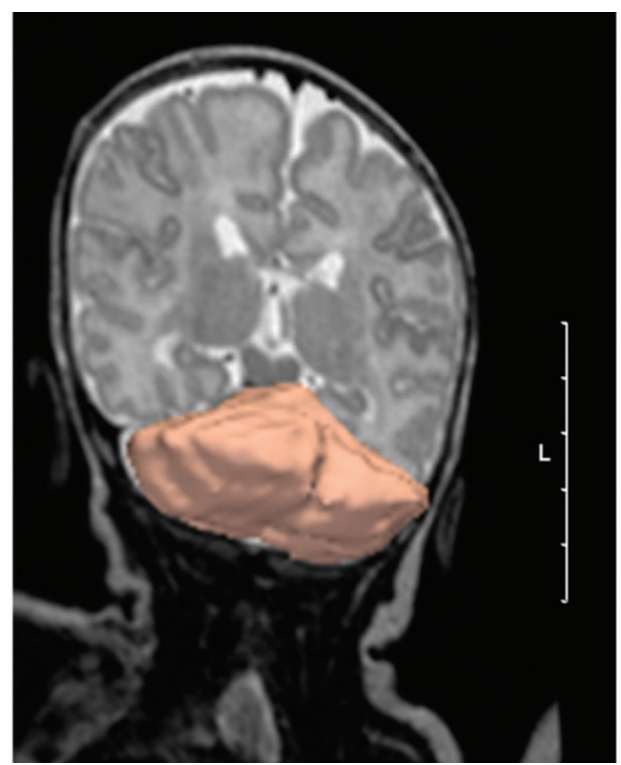

Figure 2. 3D reconstruction of manual cerebellar outlining of reconstructed 3D image slices using 3D Slicer software. (Scale bar $=5 \mathrm{~cm}, \mathrm{~L}=$ left). The figure is distorted to give a 3D impression of the cerebellum.

when no statistical differences will be found with a sample size of 20 (Power $90 \%, 10 \%$ one side significant level). Statistical analyses were performed with SPSS for windows (SPSS version: 12.0).

\section{RESULTS}

Clinical characteristics. Table 1 summarizes the clinical data of the two groups. The infants treated with hydrocortisone had lower birth weights $(826 \pm 173 \mathrm{~g}$ versus $1017 \pm$ $826 \mathrm{~g} ; p<0.05)$, without a significant difference in head circumferences at birth $(24.3 \pm 2.2 \mathrm{~cm}$ versus $25.3 \pm 1.7 \mathrm{~cm})$, compared with the control group. However, at term equivalent age they had comparable weight $(3016 \pm 735 \mathrm{~g}$ versus $3121 \pm$ $524 \mathrm{~g}, p=\mathrm{ns})$ and head circumference $(34.8 \pm 2.4 \mathrm{~cm}$ versus $35.3 \pm 1.5 \mathrm{~cm} ; p=\mathrm{ns})$. The difference between the pulmonary status of both groups was significant: The infants treated with hydrocortisone had more severe respiratory distress than the control infants, although the number of infants treated with antenatal steroids was similar for both groups ( $n=17$ versus $n=16$ ): hydrocortisone patients received more often surfactant (18 versus 8 infants, $p<0.001$ ), required a longer period of ventilation than the infants in the control group (19 versus 
Table 1. Clinical characteristics of the hydrocortisone-treated and the matched nonhydrocortisone-treated infants

\begin{tabular}{|c|c|c|c|}
\hline & $\begin{array}{c}\mathrm{HC} \\
(n=19)\end{array}$ & $\begin{array}{c}\text { CTRL } \\
(n=19)\end{array}$ & $p$ \\
\hline Gestational age (wk) & $27.0 \pm 1.4$ & $27.6 \pm 1.1$ & NS \\
\hline Birthweight (g) & $826 \pm 173$ & $1017 \pm 202$ & $<0.05$ \\
\hline Weight at term (g) & $3016 \pm 735$ & $3121 \pm 524$ & NS \\
\hline \multicolumn{4}{|l|}{ Head circumference } \\
\hline At birth $(\mathrm{cm})$ & $24.3 \pm 2.2$ & $25.3 \pm 1.7$ & NS \\
\hline At term $(\mathrm{cm})$ & $34.8 \pm 2.4$ & $35.3 \pm 1.5$ & NS \\
\hline \multicolumn{4}{|l|}{ Gender } \\
\hline Female, n (\%) & $4(21)$ & $8(42)$ & NS \\
\hline Male, $\mathrm{n}(\%)$ & $15(79)$ & $11(58)$ & NS \\
\hline Postnatal age at MRI (wk) & $41.1 \pm 0.8$ & $40.8 \pm 1.0$ & NS \\
\hline \multicolumn{4}{|l|}{ Apgar score (range) } \\
\hline At $1 \mathrm{~min}$ & $6-8$ & $2-9$ & \\
\hline At $5 \mathrm{~min}$ & $8-10$ & $5-10$ & \\
\hline Antenatal steroids, n (\%) & $16(84)$ & $17(89)$ & NS \\
\hline Assisted ventilation duration (d) & $19 \pm 8$ & $3 \pm 2$ & $<0.01$ \\
\hline Surfactant, n (\%) & $18(95)$ & $8(42)$ & $<0.01$ \\
\hline $\mathrm{CPAP}(\mathrm{d})$ & $49 \pm 34$ & $28 \pm 15$ & $<0.05$ \\
\hline $\mathrm{O}_{2}$ dependence $(\mathrm{d})$ & $71 \pm 28$ & $33 \pm 25$ & $<0.001$ \\
\hline \multicolumn{4}{|l|}{ Postnatal age at start $\mathrm{HC}$} \\
\hline Median (range) (d) & $14(7-44)$ & & \\
\hline $7-21 \mathrm{~d}(n)$ & 15 & & \\
\hline$>21 \mathrm{~d}(n)$ & 4 & & \\
\hline $\begin{array}{l}\text { Inotropic support for hypotension, } \\
\mathrm{n}(\%)\end{array}$ & $17(89)$ & $9(47)$ & $<0.05$ \\
\hline PDA, n (\%) & $14(74)$ & $9(47)$ & $<0.05$ \\
\hline NEC, n $(\%)$ & $3(16)$ & $1(5)$ & NS \\
\hline Morphine, n (\%) & $18(95)$ & $6(32)$ & $<0.001$ \\
\hline Postnatal proven sepsis, n (\%) & $12(63)$ & $6(32)$ & $<0.05$ \\
\hline
\end{tabular}

Values are expressed as mean $\pm \mathrm{SD}$.

CPAP, continuous positive airway pressure; PDA, patent ductus arteriosus; NEC, necrotizing enterocollitits.

$3 \mathrm{~d}, p<0.001$ respectively), and needed CPAP and additional oxygen for a longer period (CPAP: 49 versus $28 \mathrm{~d}, p<0.05$ and oxygen: 71 versus $33 \mathrm{~d}, p<0.001$ respectively). Finally, the hydrocortisone-treated infants needed more blood pressure support (17 versus $9, p<0.05)$ and developed more blood culture proven sepsis, mostly coagulase negative Staphylococcus (12 versus $6, p<0.05$ ). The control infants did not receive hydrocortisone or dexamethasone at any time during admission.

MRI volumetric measurements. All infants had their MRI between 38 and 43 wk postmenstrual age (Table 1). Age at MRI was equivalent between the groups $(40.8 \pm 1.0 \mathrm{wk}$ versus $41.1 \pm 0.8 \mathrm{wk}$ respectively for controls versus hydrocortisone infants). Table 2 and Fig. 3 show the results of the quantitative volumetric measurements for CGM, SGM,
UMWM, and MWM and CSF, and cerebellum. No significant differences were observed between the two groups, especially not for CGM and total cerebral and cerebellar volumes. The analyses for brain volumes were adjusted for gestational age and postmenstrual age at scan, this did not change the results.

\section{DISCUSSION}

In the present study, we compared brain development in 38 preterm infants who did or did not receive postnatal treatment with hydrocortisone for CLD. Using quantitative volumetric MRI techniques, we showed that volumes of total cerebral and cerebellar volumes, and volumes of gray and white matter were not significantly different in both groups at term equivalent age. This was even so without correction for confounding factors such as significant difference in birth weight, severity of CLD and the fact that the infants treated with hydrocortisone in the neonatal period had more complications during the first weeks of life as indicated by their pulmonary status, the higher need for inotropic support and the higher incidence of proven sepsis (16). Moreover, the volumes of all the cerebral tissue classes were comparable with previously published results, using the same advanced MRI techniques $(5,11,17-20)$.

We were able to study a larger group of infants than Murphy et al. (5), who found an impairment in brain growth, principally affecting cerebral CGM, following neonatal dexamethasone therapy in seven preterm infants using the same advanced MRI techniques. The average CGM volumes measured in hydrocortisone infants $(172 \mathrm{~mL})$ were larger than average CGM volumes in Murphy's dexamethasone infants $(130 \mathrm{~mL})$, which suggests that postnatal dexamethasone alters cerebral development in premature infants more than postnatal hydrocortisone.

Recent retrospective observational studies, using matched controls never treated with corticosteroids, already showed that preterm born infants who were treated with hydrocortisone during the neonatal period were not different with regard to cognitive, neurodevelopmental and motor outcome at 8 to $10 \mathrm{y}(9,10)$. Moreover a volumetric MRI study at $8 \mathrm{y}$ showed no differences in hippocampal and gray matter volumes in preterm born children who received hydrocortisone during the neonatal period compared with a matched control group of children born preterm (8). These retrospective observational studies already suggested that the use of hydrocortisone for treatment of CLD did not adversely affect neurodevelopmental

Table 2. Volumes in mean \pm SD (confidence interval 95\%) and the mean difference (confidence interval 95\%) of the various tissue classes measured by $3 D$ volumetric MRI (in milliliters) without statistical difference $(\mathrm{p}<0.05)$

\begin{tabular}{|c|c|c|c|}
\hline & $\mathrm{HC}(n=19)$ & CTRL $(n=19)$ & $\begin{array}{c}\text { Mean difference } \\
\text { (confidence interval 95\%) }\end{array}$ \\
\hline Cortical gray matter & $172 \pm 32(155-183)$ & $183 \pm 38(172-199)$ & $-10(-34$ to 12$)$ \\
\hline Unmyelinated white matter & $177 \pm 27(162-191)$ & $194 \pm 32(180-209)$ & $-17(-37$ to 3$)$ \\
\hline Myelinated white matter & $8.3 \pm 2.2(7.1-9.5)$ & $8.7 \pm 2.8(7.7-10.0)$ & $-0.4(-2.1$ to 1.2$)$ \\
\hline Subcortical gray matter & $19 \pm 3(17-21)$ & $21 \pm 4(19-22)$ & $-2(-4$ to 1$)$ \\
\hline Cerebrospinal fluid & $49 \pm 18(37-58)$ & $57 \pm 27(48-68)$ & $-8(-23$ to 7$)$ \\
\hline Total cerebral volume & $377 \pm 52(349-398)$ & $407 \pm 62(385-435)$ & $-30(-68$ to 8$)$ \\
\hline Total intracranial volume & $425 \pm 63(393-449)$ & $464 \pm 70(440-496)$ & $-38(-82$ to 5$)$ \\
\hline Cerebellum & $23 \pm 4(19-25)$ & $24 \pm 4(20-26)$ & $-1(-4-2)$ \\
\hline
\end{tabular}





Figure 3. Cerebral cortical gray matter volumes, total cerebral tissue, and cerebellar volume in preterm infants at term who were never treated with postnatal hydrocortisone (CTRL) $(n=19)$, and preterm infants at term previously treated with postnatal hydrocortisone (HC; $n=19)$ (expressed as means with 2 SD bars).

outcome, in contrast to the prospective randomized controlled studies that showed an adverse effect of dexamethasone used for this indication $(2,3,21)$.

Although it is still to be shown that shorter courses of dexamethasone with lower dosages, used nowadays to treat CLD of prematurity, also have an adverse effect on neurodevelopmental outcome, there are several reasons to use hydrocortisone rather than dexamethasone. The impact of glucocorticosteroid exposure on the developing brain is dependent on the expression of mineralocorticoid receptors and glucocorticoid receptors on the neurons and microglial cells and the affinity of a particular glucosteroid for these receptors $(22,23)$. Hydrocortisone has a mainly mineralocorticoid-mediated activity and a much shorter half-time $(8-12 \mathrm{~h})$ compared with dexamethasone which has mainly a glucocorticosteroidmediated action, a much longer half time (up to $48 \mathrm{~h}$ ) triggering accumulation in the brain and an anti-inflammatory action up to 25 to 30 times higher than hydrocortisone (24). Moreover, animal studies have shown that activation of glucocorticoid receptors lead to adverse effects on neuronal cells such as promotion of apoptotic activity of granular cells in the hippocampus (1). In contrast to glucocorticoid receptors, mineralocorticoid receptors are protective against apoptosis by up-regulation of anti-apoptotic proteins. Another mechanism may also play an important role here: $11-\beta$-hydroxysteroid dehydrogenase type 2 , which has a high expression in the fetal brain and several regions of the neonatal brain, acts as hydrogenase, inactivating cortisol (hydrocortisone is equivalent to cortisol) through conversion to dehydrocorticosterone and cortisone. Thus, it protects against abundant mineralocorticoid receptors and glucocorticoid receptors binding of exogenous corticosteroid exposure. This mechanism does not apply to exogenous dexamethasone treatment since this compound cannot be converted by $11-\beta$-hydroxysteroid dehydrogenase type 2, which may, at least partly, explain the negative effect of dexamethasone on brain development compared with hydrocortisone. Loss of 11- $\beta$-hydroxysteroid dehydrogenase type 2 from the fetus and fetally derived tissue has been shown to alter development of the cerebellum $(25,26)$. Although lowering the dose of dexamethasone could be one strategy to prevent abundant glucocorticoid receptors binding by dexa- methasone, lower dosages used in the study of Parikh et al. (6) still affected brain growth.

Given the results of the present study, the circumstantial evidence provided by several retrospective matchedcontrolled studies, the above mentioned considerations and the fact that it seems to be clinically as effective as dexamethasone (7), we would suggest that hydrocortisone is a better choice than dexamethasone for the treatment of CLD in preterm infants.

Nevertheless, the present study has several limitations, like the relatively small number of patients included and the fact that the matched controls were partly derived from a different institution (the University Hospital of Geneva) compared with the hydrocortisone patients who all came from one center (the Wilhelmina Children's Hospital of the University Medical Center Utrecht). At the time of this study, it was not yet routine to perform MRI at term equivalent age in high-risk preterm infants. Permission for an MRI at term equivalent age was not often obtained in the absence of severe intracranial lesions and when no hydrocortisone treatment was given. Geneva has a long-standing reputation as a center of expertise for performing neonatal MRI, also for infants with less severe neonatal problems. Since antenatal and neonatal intensive care treatment policies of very low birth weight infants and population backgrounds are comparable between these two hospitals and MRI acquisition protocols at term equivalent age were identical, combining data from the two centers was considered acceptable. MRI measures of tissue volume may be impacted by differences of MRI electronics noise, by gradient nonlinearity, by B0 and B1 inhomogeneities, and by subject-specific physiologic factors. However, the impact of these MRI phenomena is much smaller than the inter-subject variability in tissue volume, and so we did not attempt to measure or compensate for these phenomena (27).

Segmentation of the newborn brain MRI is challenging due to the small size of the developing brain. With the intensity of UMWM being somewhere between gray matter and CSF, partial volume averaging between these two tissues may result in small misclassification at border zones of these two tissues, which is a limitation of the technique. However, the algorithm used here has been developed and validated specifically for 
neonatal brain MRI. Validation experiments have demonstrated the tissue classification algorithm has high reproducibility (13), and is robust in the presence of signal intensity artifact (14). Comparison of estimates of CSF volumes from MRI to fluid removed indicates the algorithm has high absolute accuracy (28).

It is also unlikely that under powering of the study may have prevented a reliable result: in spite of the fact that the hydrocortisone group consisted of sicker prematurely born infants with lower birth weights, who had a higher need for inotropic support because of hypotension and more intense ventilatory support with significantly higher oxygen needs, and were more often affected by a septicemia, which was recently shown to adversely affect the white matter $(16,29)$, no difference in MRI-determined brain development was detected compared with a healthier control group. Rather than to prolong the study period by trying to collect all infants in one NICU-center, we choose for the best possible matching by collaborating with Geneva, where the volumetric analysis was performed.

In conclusion, in this small group of preterm infants we were unable to show an adverse effect of hydrocortisone on cerebral growth at term equivalent age, using volumetric 3D-MRI techniques. The preterm infants who received hydrocortisone for severe respiratory problems were compared with age-matched controls who experienced less severe respiratory problems and were less often affected by a septicemia. This study would support our previous retrospective observational long-term follow-up data after neonatal treatment with hydrocortisone in contrast to dexamethasone treatment. We nowadays tend to restrict neonatal corticosteroid therapy to exceptional clinical conditions. When corticosteroid therapy is considered, hydrocortisone may be a safer alternative than dexamethasone. A randomized controlled trial for hydrocortisone would be welcome to possibly further substantiate our findings.

Acknowledgment We thank M.H. Tas, medical student, for collecting the clinical data.

\section{REFERENCES}

1. Uno H, Eisele S, Sakai A, Shelton S, Baker E, DeJesus O, Holden J 1994 Neurotoxicity of glucocorticoids in the primate brain. Horm Behav 28:336-348

2. O'Shea TM, Washburn LK, Nixon PA, Goldstein DJ 2007 Follow-up of a randomized, placebo-controlled trial of dexamethasone to decrease the duration of ventilator dependency in very low birth weight infants: neurodevelopmental outcomes at 4 to 11 years of age. Pediatrics 120:594-602

3. Yeh TF, Lin YJ, Lin HC, Huang CC, Hsieh WS, Lin CH, Tsai CH 2004 Outcomes at school age after postnatal dexamethasone therapy for lung disease of prematurity. N Engl J Med 350:1304-1313

4. Barrington KJ 2001 Postnatal steroids and neurodevelopmental outcomes: a problem in the making. Pediatrics 107:1425-1426

5. Murphy BP, Inder TE, Hüppi PS, Warfield S, Zientara GP, Kikinis R, Jolesz FA, Volpe JJ 2001 Impaired cerebral cortical gray matter growth after treatment with dexamethasone for neonatal chronic lung disease. Pediatrics 107:217-221
6. Parikh NA, Lasky RE, Kennedy KA, Moya FR, Hochhauser L, Romo S, Tyson JE 2007 Postnatal dexamethasone therapy and cerebral tissue volumes in extremely low birth weight infants. Pediatrics 119:265-272

7. van der Heide-Jalving M, Kamphuis PJ, van der Laan MJ, Bakker JM, Wiegant VM Heijnen CJ, Veen S, van Bel F 2003 Short- and long-term effects of neonatal glucocorticoid therapy: is hydrocortisone an alternative to dexamethasone? Acta Paediatr 92:827-835

8. Lodygensky GA, Rademaker K, Zimine S, Gex-Fabry M, Lieftink AF, Lazeyras F, Groenendaal F, de Vries LS, Hüppi PS 2005 Structural and functional brain development after hydrocortisone treatment for neonatal chronic lung disease. Pediatrics 116:1-7

9. Karemaker R, Heijnen CJ, Veen S, Baerts W, Samsom J, Visser GH, Kavelaars A, van Doornen LJ, van Bel F 2006 Differences in behavioral outcome and motor development at school age after neonatal treatment for chronic lung disease with dexamethasone versus hydrocortisone. Pediatr Res 60:745-750

10. Rademaker KJ, de Vries LS, Uiterwaal CS, Groenendaal F, Grobbee DE, van Bel F 2008 Postnatal hydrocortisone treatment for chronic lung disease in the preterm newborn and long-term neurodevelopmental follow-up. Arch Dis Child Fetal Neonatal Ed 93:F58-F63

11. Hüppi PS, Warfield S, Kikinis R, Barnes PD, Zientara GP, Jolesz FA, Tsuji MK Volpe JJ 1998 Quantitative magnetic resonance imaging of brain development in premature and mature newborns. Ann Neurol 43:224-235

12. Inder TE, Warfield SK, Wang H, Hüppi PS, Volpe JJ 2005 Abnormal cerebra structure is present at term in premature infants. Pediatrics 115:286-294

13. Warfield SK, Kaus M, Jolesz FA, Kikinis R 2000 Adaptive, template moderated, spatially varying statistical classification. Med Image Anal 4:43-55

14. Warfield SK, Zou KH, Wells WM 2004 Simultaneous truth and performance level estimation (STAPLE): an algorithm for the validation of image segmentation. IEEE Trans Med Imaging 23:903-921

15. Limperopoulos C, Soul JS, Gauvreau K, Hüppi PS, Warfield SK, Bassan H, Robertson RL, Volpe JJ, du Plessis AJ 2005 Late gestation cerebellar growth is rapid and impeded by premature birth. Pediatrics 115:688-695

16. Shah DK, Doyle LW, Anderson PJ, Bear M, Daley AJ, Hunt RW, Inder TE 2008 Adverse neurodevelopment in preterm infants with postnatal sepsis or necrotizing enterocolitis is mediated by white matter abnormalities on magnetic resonance imaging at term. J Pediatr 153:170-175

17. Thompson DK, Warfield SK, Carlin JB, Pavlovic M, Wang HX, Bear M, Kean MJ, Doyle LW, Egan GF, Inder TE 2007 Perinatal risk factors altering regional brain structure in the preterm infant. Brain 130:667-677

18. Mewes AU, Hüppi PS, Als H, Rybicki FJ, Inder TE, McAnulty GB, Mulkern RV, Robertson RL, Rivkin MJ, Warfield SK 2006 Regional brain development in serial magnetic resonance imaging of low-risk preterm infants. Pediatrics 118:23-33

19. Zacharia A, Zimine S, Lovblad KO, Warfield S, Thoeny H, Ozdoba C, Bossi E, Kreis R, Boesch C, Schroth G, Hüppi PS 2006 Early assessment of brain maturation by MR imaging segmentation in neonates and premature infants. AJNR Am J Neuroradiol 27:972-977

20. Tolsa CB, Zimine S, Warfield SK, Freschi M, Sancho Rossignol A, Lazeyras F, Hanquinet S, Pfizenmaier M, Hüppi PS 2004 Early alteration of structural and functional brain development in premature infants born with intrauterine growth restriction. Pediatr Res 56:132-138

21. Shinwell ES, Karplus M, Reich D, Weintraub Z, Blazer S, Bader D, Yurman S, Dolfin T, Kogan A, Dollberg S, Arbel E, Goldberg M, Gur I, Naor N, Sirota L, Mogilner S, Zaritsky A, Barak M, Gottfried E 2000 Early postnatal dexamethasone treatment and increased incidence of cerebral palsy. Arch Dis Child Fetal Neonatal Ed 83:F177-F181

22. Almeida OF, Condé GL, Crochemore C, Demeneix BA, Fischer D, Hassan AH, Meyer M, Holsboer F, Michaelidis TM 2000 Subtle shifts in the ratio between proand antiapoptotic molecules after activation of corticosteroid receptors decide neuronal fate. FASEB J 14:779-790

23. Sousa N, Cerqueira JJ, Almeida OF 2008 Corticosteroid receptors and neuroplasticity. Brain Res Rev 57:561-570

24. Taketomo CK, Hodding JH, Kraus DM 2004 Pediatric Dosage Handbook. 11th ed Lexi-Comp, Hudson, $\mathrm{OH}$

25. Holmes MC, Seckl JR 2006 The role of 11 beta-hydroxysteroid dehydrogenases in the brain. Mol Cell Endocrinol 248:9-14

26. Holmes MC, Sangra M, French KL, Whittle IR, Paterson J, Mullins JJ, Seckl JR 200611 beta-Hydroxysteroid dehydrogenase type 2 protects the neonatal cerebellum from deleterious effects of glucocorticoids. Neuroscience 137:865-873

27. Jovicich J, Czanner S, Greve D, Haley E, van der Kouwe A, Gollub R, Kennedy D, Schmitt F, Brown G, Macfall J, Fischl B, Dale A 2006 Reliability in multi-site structural MRI studies: effects of gradient non-linearity correction on phantom and human data. Neuroimage 30:436-443

28. Hunt RW, Warfield SK, Wang H, Kean M, Volpe JJ, Inder TE 2003 Assessment of the impact of the removal of cerebrospinal fluid on cerebral tissue volumes by advanced volumetric 3D-MRI in posthaemorrhagic hydrocephalus in a premature infant. J Neurol Neurosurg Psychiatry 74:658-660

29. Glass HC, Bonifacio SL, Chau V, Glidden D, Poskitt K, Barkovich AJ, Ferriero DM, Miller SP 2008 Recurrent postnatal infections are associated with progressive white matter injury in premature infants. Pediatrics 122:299-305 